\title{
A Comparative Study of Differences in Government Regulation of Food Safety between China and the United States
}

\author{
En Huang, Xun Dai, Zhuolan Li \\ En Huang, Xun Dai, Zhuolan Li, School of Economics and Management, Wuhan Polytechnic \\ University, Wuhan, China.
}

Keywords: Safety supervision, quality standards, international certification, regulation.

\begin{abstract}
This paper analyzes the present situation of domestic food safety regulatory system, and comparative analysis of the gap between China and the US food safety regulatory systems that exist in regulation, and the regulation of food safety issues in all types of research, suggested that the domestic food safety supervision departments should learn from the mature experience of their US counterparts, strengthen the dominant position of the regulatory bodies and regulatory authorities continue to improve laws and regulations, the introduction of risk assessment mechanism, reduce the probability of occurrence of various types of food safety risks.
\end{abstract}

\section{Introduction}

Choosing a sound regulatory regime and setting a reasonable regulatory body are solid foundations for deciding whether or not to effectively enforce regulation. For the food safety regulatory agencies, no one organization function is perfect, the selection of regulatory model and the national economic and technological development level, social system and cultural background. Major developed countries have proven experience in the regulation of food safety and have accumulated a great deal of practical experience through years of development, especially in terms of regulatory mechanisms and legislative and regulatory functions. Major developed countries have more mature food safety regulatory system to support the production and operation of their own food businesses, and many food enterprises in developed countries also adopt the international quality standard management system (HACCP-ISO22000) to organize production operations and continue Improve the standardization of products to enhance the competitiveness of enterprises. Some traditional food manufacturers, but also achieved the most international quality standard certification, and will ensure product quality rose to the height of the strategic development of enterprises. They attach great importance to continuous improvement of product quality and continuous improvement of production processes and processes in order to achieve continuous improvement of product quality. China has the largest population in the world and is also a large consumer of food. There are many domestic food enterprises. However, these enterprises are very weak in their awareness of food safety and they are not strong in obtaining international certification of food quality and organizing production according to the standards. At present, the domestic food safety regulatory system is not perfect, the food quality standard system is not perfect, and the regulatory measures are not in place. There are also many loopholes in the regulatory legislation, which will be extremely unfavorable for improving the quality stability of our food industry and expanding the export of products situation.

\section{China's Food Safety Regulations in the Government: There are Various Types of Problems}

The issue of food safety in our country has drawn much attention from all parties. Food safety incidents have also occurred frequently. These problems have aroused strong resentment among the general public. The unfavorable factors that restrict the regulatory efficiency of food safety are mainly reflected in the following aspects:

\subsection{The Lack of Legislation System of Domestic Food Safety Regulations}

China's food safety regulatory system is imperfect, and the United States and other food safety regulatory system than the more mature countries, the country is still in the early stages of food safety 
legislation. Several food safety laws have been promulgated: the Food Safety Law, the Law on the Quality and Safety of Agricultural Products and the Law on the Inspection of Import and Export Commodities. And already promulgated "Food Safety Law" laws and regulations, only the "Food Safety Law Regulations" and "Food Safety Implementation Regulations", and these comprehensive laws, there is no specific provisions for specific regulatory targets, nor for food Production and circulation aspects of the legal provisions [1]. The current laws and regulations on the law enforcement involved in food safety violations are not strong enough. Due to the lack of law enforcement, which led to many catering industries in order to reduce costs, the use of waste oil instead of green and healthy cooking oil, or even direct use of waste oil instead of cooking oil has become part of the unspoken rules of the restaurant industry.

\subsection{Lack of External Supervision of Honest Operation of Food Enterprises}

Due to the traditional food production mode has led to the original single-style government supervision failure, and our long-standing dualistic economy also led to many domestic food enterprises simple and extensive mode of production, especially in the field of food processing, there are many Small-scale enterprises. Their production conditions are poor and their production technology is very low. According to relevant statistics, food production enterprises that obtain food hygiene licenses in the country account for only $1 / 6$ of the total number of food enterprises, and the scale of enterprises is generally small. There are also a large number of hand-workshop, there are $64 \%$ of food companies never test the quality of manufactured products, $25 \%$ of enterprises have no standard production, 15\% of enterprises without permits production. This backward approach to food production has had the serious consequence of a weak awareness of producers about food safety, leading to vicious competition and ignoring food quality. In order to adapt themselves to the self-discipline of the market sectors, they have been slow to develop. The lack of management mechanisms for mutual supervision and self-discipline within the industry and the comprehensive supportive measures for punishing and dishonesty have yet to be perfected. As a result, many food producers and marketers now lack moral morals the lack of integrity of the situation. In the face of the temptation of the market and interest, the lack of honesty and credit, fame and fortune, fake fraud and evasion of punishment are widespread in the producers of enterprises, lacking in legal awareness of being responsible for the products and being responsible for the society. In addition, in order to reap huge profits, Breach of law and morality, to the law regardless, desperation [2].Many food safety incidents are found in the production and processing sectors of enterprises. In the face of a large number of unevenly distributed production and operation units, government supervision by a single model appeared to be very weak. As a result, frequent incidents of food safety incidents in China The situation, as shown in Table 1.

Table 1. Statistics report domestic food safety incidents in 2001-2014

\begin{tabular}{|c|c|c|c|}
\hline Years & Poisoning report example & The number of poisoning & Death toll \\
\hline 2001 & 185 & 15715 & 146 \\
\hline 2002 & 128 & 7127 & 138 \\
\hline 2003 & 379 & 12876 & 323 \\
\hline 2004 & 347 & 12467 & 274 \\
\hline 2005 & 256 & 9021 & 235 \\
\hline 2006 & 596 & 18063 & 198 \\
\hline 2007 & 506 & 13280 & 258 \\
\hline 2008 & 431 & 13095 & 154 \\
\hline 2009 & 271 & 11007 & 181 \\
\hline 2010 & 220 & 7383 & 137 \\
\hline 2011 & 189 & 8324 & 146 \\
\hline 2012 & 174 & 6685 & 109 \\
\hline 2013 & 152 & 5559 & 110 \\
\hline 2014 & 160 & 5657 & 170 \\
\hline
\end{tabular}

Note: Data from the Ministry of Health of China on the adoption of food safety incidents, 2001-2014. 
From 2001 to 2014, the reported cases of food poisoning cases from 2001 to 2006 show an increasing trend year by year. The number of poisoning cases has also been increasing year by year, and it is still at a high-volume benchmark by 2014. In the domestic annual food poisoning reporting incidents, a large proportion of food poisoning incidents caused by microbial food poisoning, which shows the unprecedented task of food safety regulatory tasks of the arduous and complex, as shown in Figure 1

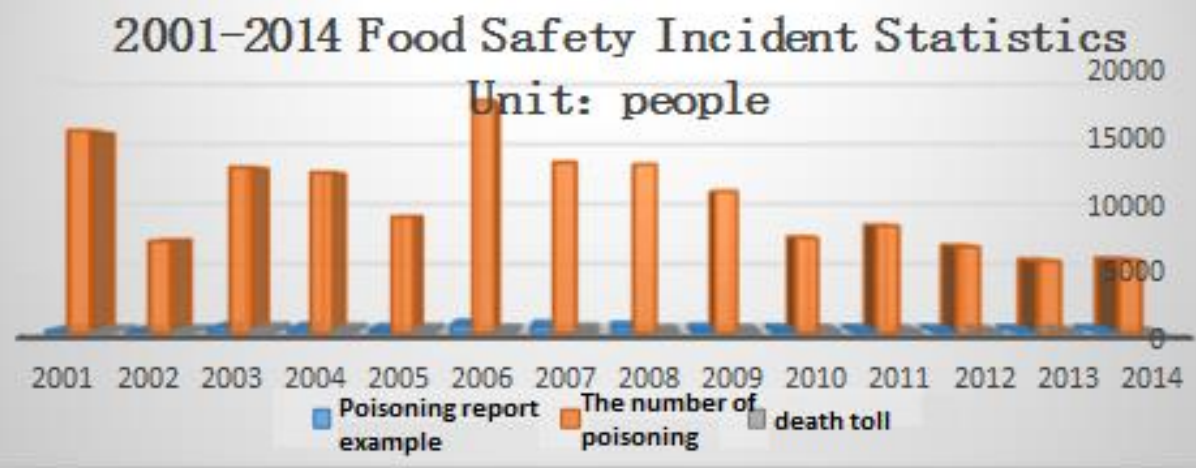

Figure 1. 2001-2014 Food Safety event chart

\subsection{Food Safety Technical Standards System is Not Perfect}

The overall level of China's food safety standards is low, there is cross-functional overlap, duplication and contradiction between the national standards, industry standards and local standards. Some of the industry standards are lower than the national standards. Important standards of detection technology is missing, some products cannot be standard, and the scientific basis for the development of standards need to be improved. Due to the lack of risk assessment data, it restricts the domestic standard of residue, but the method and system of standard development cannot meet the needs of the food safety supervision, and the implementation of the standard is not strict and so on.

\subsection{The Functions of Food Safety Regulatory Agencies are Not Set Properly}

The functional setup of China's food safety regulatory agencies shows the characteristics of multisectoral management, link-level management and regional management. Its functional supervision departments mainly include: quality inspection departments, food and drug supervision departments, commercial departments, agricultural departments, health departments, industrial and commercial departments, environmental protection departments and the financial sector more than 10 departments. These departments can all supervise food safety issues. The regulatory model is a regulatory mechanism where one regulatory body is regulated by only one agency and adopts sub-regulation as its main body and supplemented by variety control. Although the regulatory functions of different departments have been divided, but there are still some problems such as poor communication among management departments, imperfect functional systems and weak grass-roots management departments. Law enforcement team and equipment, funding, technical support system, etc. are not suited to the actual needs of serious, legislation, standards and systems are lagging behind. In the process of actual supervision, there are also some problems such as lack of regulatory responsibility and lax enforcement [3]. In particular, the issue of imperfect food safety regulatory system is very prominent, which is very detrimental to the coordination between various departments, the regulatory process is also prone to blank areas.

\section{The Difference Between the Government Regulatory Functions of Food Safety in China and the United States}

\subsection{Domestic and Foreign Food Safety Inspection Standard System Gap}

Europe and the United States have developed a sound food safety testing system, with strict testing methods, the specific provisions of food safety rules, and fundamentally guaranteed the effective 
implementation of food safety laws and regulations. The domestic food safety inspection standards with large gaps between international standards, this gap has led to frequent occurrence of domestic food safety situation, the gap between the food safety inspection standards are mainly reflected in the following areas:

\subsubsection{Test Hardware and Inspection Ability is Weak, Lack of Ability to Verify the System and Standardization}

1) Hardware and software conditions. Most of the food quality inspection agencies in the United States, have high efficiency and technical authority, mainly because they attach great importance to the ability of testing agencies, attach importance to the accumulation of hardware and software testing agencies, especially the construction of two connotations: Test conditions and professionals. Among the testing organizations in the United States, laboratories set up by the government are usually well-equipped and well-equipped. The United States also attaches great importance to the strict selection and employment of professionals. Inspection professionals have high professional qualifications and academic qualifications.

2) Detection capability. The United States has formed between the various food inspection agencies scale, high precision and high technology. They tend to improve their testing capabilities by increasing the level of automation and increasing the number of instrumentation, such as the scale-up of inspections: Fares now's CSP in the California Department of Agriculture employs less than 40 people but has nine gas-phase Chromatographs, which are not only capable of detecting but also highly stable, can detect tens of thousands of samples from each state each year [5].

3) Proficiency test. Competency verification is a method of objective assessment of laboratory level and management status. It belongs to a way of accreditation of laboratories and maintains follow-up supervision and inspection. Through the ability to verify, you can discover the problems in the laboratory, and monitor the operation of the laboratory to improve laboratory testing capabilities to ensure that the quality of inspection certificates. In the United States, laboratory proficiency testing has been institutionalized and standardized. Proficiency testing is also an internationally accepted means of evaluating laboratory test reports/certificates.

\subsubsection{The Characteristics of the Legislative System of Food Safety Regulation in the United States}

Food safety legislation is the cornerstone of the United States food safety regulatory system, which determines the functional division of the US food safety regulatory agencies and scope, and the system to ensure that the US food safety regulatory mechanism. As early as 1890, the United States has enacted the "Federal Meat Inspection Law", which marks the beginning of the United States food safety legislation, after a hundred years of precipitation, the United States has formed a law consisting of 40 food safety laws System that basically covers all food industries and details the standards and regulatory enforcement procedures for food safety, all of which fall into four categories: (1) comprehensive laws such as the Federal Food, Drug and Cosmetic Act As the basic laws and regulations on food and drug in the United States, it has become the most comprehensive one of similar laws in the world after many revisions. It is also the core of the U.S. laws and regulations on food safety. It also establishes the framework of food safety regulation in the United States. (2) The regulatory laws that are based on the type of food, such as the Egg Inspection Act; (3) The laws and regulations enacted at all stages of the food circulation, such as "Proper Packaging and Labeling Law";(4) According to the relevant laws of food production investment, such as" insecticides, fungicides and rodenticides"(such as Table2) [6].In the United States food safety regulatory body established by the laws and regulations, food safety regulation of the relevant content for further regulation, and continuous revision.

The United States Federal Code, a permanent federal statute, and the U.S. Code of Decrees developed by the House of Representatives, and the Food Safety Modernization Act, passed in November 2010, allow the U.S. Food and Drug Administration Have more rights [7]. And these legal provisions in the protection of the United States in the field of food safety to build a very powerful system, and very perfect. 
Table 2. Related legislation us food safety regulation

\begin{tabular}{|c|c|c|}
\hline Law type & Legal Name & Main Content \\
\hline $\begin{array}{l}\text { Comprehensive } \\
\text { law }\end{array}$ & $\begin{array}{l}\text { Federal Food, Drug and Cosmetic Act } \\
\text { (FFDCA) }\end{array}$ & $\begin{array}{l}\text { Including the control of food counterfeit, normative labe } \\
\text { ling, emergency, pesticide residue standards, additives, } \mathrm{f} \\
\text { ood companies, toxic ingredients limited }\end{array}$ \\
\hline $\begin{array}{l}\text { Various food } \\
\text { safety laws }\end{array}$ & PACA, USGSA, EPIA, FMIA, PPIA etc. & $\begin{array}{l}\text { Provisions on the hygiene, packaging, certification, tran } \\
\text { sportation, destruction and penalties of } \\
\text { food products such as products, eggs, meat and poultry }\end{array}$ \\
\hline $\begin{array}{l}\text { Food circulation } \\
\text { method }\end{array}$ & $\begin{array}{c}\text { Proper Packaging and Labeling Act } \\
\text { (EPLA),Food Sanitation Transport Act } \\
\text { (SFTA),Federal Import Dairy Act } \\
\text { (FIMA),etc. }\end{array}$ & $\begin{array}{l}\text { Including the use of tools, inspection, management, } \\
\text { penalties, exemptions and so on. }\end{array}$ \\
\hline $\begin{array}{l}\text { Food production } \\
\text { input method }\end{array}$ & $\begin{array}{l}\text { Food Quality Assurance Act (FQPA), Pe } \\
\text { sticides, Fungicides and Rodenticides Ac } \\
\text { t (FIFRA) }\end{array}$ & Pesticide residue standards, pesticide registration \\
\hline
\end{tabular}

Note: The information comes from Shanghai Scientific Information Technology Institute (ISTIS)

\section{Us Food Safety Government Regulatory Functions of the Agency}

American citizens attach great importance to food safety issues, and food safety regulation is also a major aspect of government functions. Before 1998, the food safety regulatory system in the United States was a piecemeal management system for various departments. However, after the continuous reform by the government, a system of public safety supervision of food safety has been established that integrates comprehensiveness and harmonization.

At this stage of the United States food safety regulatory system is a relatively centralized regulatory system, and in accordance with the type of food regulatory functions of the division of different types of food will be placed under the supervision of different departments, and the department responsible for the corresponding food production and all Supervision of circulation, including from planting, breeding, production, processing to sales and logistics and other sectors. There are three departments that mainly perform supervisory functions: USDA, DHHS, and FSIS [8]. The three regulators exercised their key food safety regulatory powers and assumed important regulatory responsibilities. The three departments have close cooperation and good communication. They meet each other every month. They have both division of work and cooperation to ensure effective implementation of food safety measures. The food regulatory law enforcement agencies across the state established throughout the United States are largely the federal government, while the food safety regulation in each state is controlled by the state. The main function of the Presidential Food Safety Management Committee established in 1998 is to coordinate food safety within the United States. Members of the committee come from the Ministry of Agriculture, the Ministry of Commerce, the Department of Health and Human Services, the Budget Office, the Environmental Protection Agency, Science and Technology Policy Office and other related functional departments responsible for the chairman of the Committee by the Minister of Agriculture, Health and Human Services minister, director of science and technology policy office together and formed the nation's food safety regulatory troika, as shown in picture 2. 


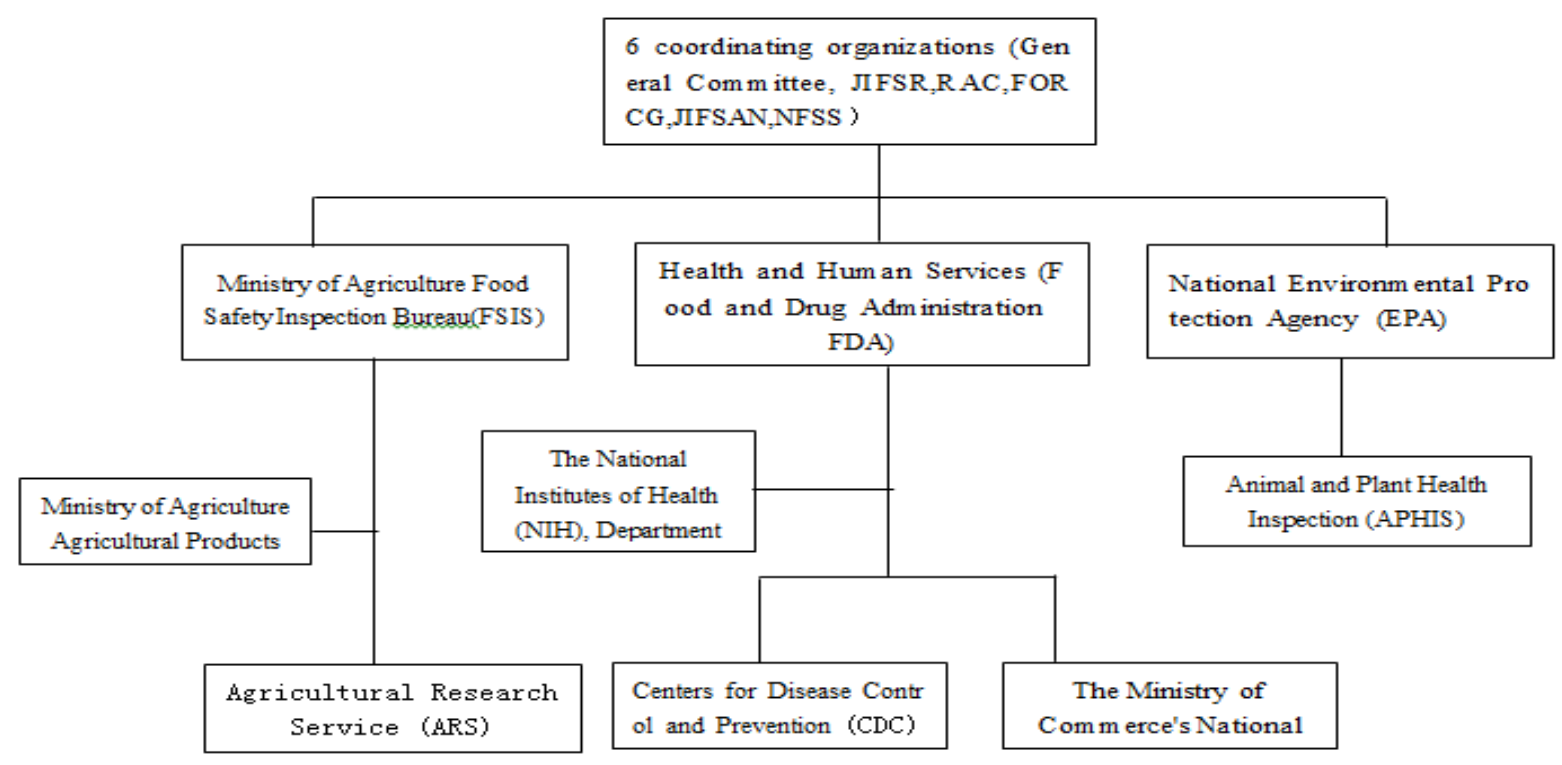

Figure 2. US food safety regulatory functions of the body

The number of food safety regulators in the United States is very large. However, most regulatory functions are concentrated in a few relatively concentrated departments and the regulatory efficiency is enhanced by increasing cooperation between departments. The responsibilities and powers of the relevant regulatory authorities are clear, with tacit understanding and regulatory measures in place, the regulatory level is also rising, and its regulatory functions are mainly reflected.

\section{Conclusion}

Mature food safety regulatory system is conducive to maximize the effectiveness of food safety regulatory policies, so many developed countries are committed to establishing a suitable food safety regulatory system. And their domestic food safety regulatory system are more perfect and efficient operation. At present, food safety problems frequently occur in the domestic food industry. Some incidents have caused very serious consequences such as "San Lu milk powder", "Clematis" and "big doll", which reflect the domestic regulatory framework for food safety System imperfections: such as lax enforcement, impunity and many other phenomena, which also led to food companies in order to make money at any cost, resulting in frequent food safety incidents. The food processing enterprises in the United States and other countries generally adopt the Food Quality Management System (HACCP) and organize production accordingly, thus ensuring product quality. In particular, the surveillance and punishment on food safety in Europe and the United States are very strict, The cost of illegal food enterprises is also very high, and food bankruptcies caused by food safety problems continue to occur, thus effectively protecting the diet of their own people, the experience of these foreign colleagues are worth learning from domestic enterprises. At the 5th Plenary Session of the 18th CPC Central Committee in 2015, President Xi Jinping emphasized at the conference: To establish a new green agricultural development concept, resolutely control the pollution problem and earnestly safeguard "food safety." Therefore, the current state attaches great importance to food safety issues that concern people's livelihood and we must implement it in a down-to-earth manner.

\section{Acknowledgements}

This work was supported by The Humanities and Social Sciences Youth Fund Project of Education Department of Hubei Province in 2018 (18G247); The Soft Science Project of Hubei Grain Bureau in 2018; The Research Project of Hubei Provincial Department of Education in 2018; the Research Project of Wuhan Polytechnic University in 2016 (201701). 


\section{References}

[1]. Liu Yanhui, Liang Zhichao, Chen Qian. Ability Verification of Green Food Quality Control Agency. Chinese Food and Nutrition, 2011, (09): 28-30.

[2]. Han Peng. China's food safety regulatory system problems and countermeasures. Shandong: Shandong University, 2010.

[3]. Chen Weikang, Luo Le. Developed countries, food safety regulatory research and its implications. Guangdong Agricultural Sciences, (8) 22-25.

[4]. Han Hongxiang. Research on Administrative Legal Liability in China's Food Safety Regulatory [D]. Shanghai: Fudan University, Shanghai, 2012.

[5]. Huang En, Long Ziwu, Li Xiaotao. Comparison of agricultural products quality safety standards between China and foreign countries. Journal of South Central University for Nationalities, Science and Technology, 201433 (2): 137-142.

[6]. Huang Yi, Wang Tingli. A Review of Foreign Theoretical Studies on Food Safety. Productivity Research, 2010 (10): 36-42

[7]. Zhang Tianyi. China's food safety supervision of government research. Changchun: Jilin University of Finance and Economics, 2013.

[8]. Yao Shuiqiong. European countries and the United States food safety inspection monitoring and supervision of the characteristics and implications. Food and Machinery, 2011 (1): 16-19.

[9]. Edward I. Broughton and Damian G. Walker, Policies and Practices for Aquaculture Food Safety in China Food Policy.Vol35,N0.5,2010,pp.471-478.

[10]. Mikael Klintman and Annica Kronseell, Challenges to Legitimacy in Food Saftey Governance? The Case of the European Food Safety Authotity. Joural of European Integration, Vol32, No3, 2010, pp.309-327

[11]. Ching-Fu Lin, Global Food Safty: Exploring Key Elements for an International Regulatory Strategy.Virginia Journal of International Law, Vol 51, No3, 2011, PP.637-695. 